\title{
Patient Radiation Protection Covers for Head CT Scans - A Clinical Evaluation of Their Effectiveness
}

\section{Patientenstrahlenschutzabdeckungen bei Kopf-CTs - Eine klinische Evaluierung ihrer Effektivität}

Authors

Affiliations
M. Liebmann ${ }^{1,4}$, T. Lüllau ${ }^{1,4}$, A. Kluge ${ }^{2}$, B. Poppe ${ }^{1,4}$, H. von Boetticher ${ }^{3}$

Medical Radiation Physics, Carl von Ossietzky University, Oldenburg

Institute for Diagnostic and Interventional Radiology, Pius-Hospital Oldenburg

Center of Radiology/Nuclear Medicine and Academy of Radiation Protection, Klinikum Links der Weser, Bremen

Clinic for Radiotherapy and Radiooncology, Pius-Hospital Oldenburg
Key words

- $\mathrm{CT}$

- head/neck

- radiation safety

- technical aspects

received $\quad 18.11 .2013$

accepted $\quad 25.2 .2014$

Bibliography

Dol http://dx.doi.org/

$10.1055 / \mathrm{s}-0034-1366279$

Published online: 1.4.2014

Fortschr Röntgenstr 2014; 186:

1022-1027 @ Georg Thieme

Verlag KG Stuttgart · New York .

ISSN 1438-9029

Correspondence

Mario Liebmann

Medizinische Strahlenphysik, Carl von Ossietzky Universität Ammerländer Heerstraße 114-118

26129 Oldenburg

Germany

Tel.: ++ 49/0441/2291633

Fax: ++ 49/04 41/2291645

mario.liebmann@uni-

oldenburg.de

\section{Zusammenfassung}

$\nabla$

Ziel: Obwohl der Einsatz von Abschirmungen der Schilddrüse bei Schädel-CT-Untersuchungen vernünftig und sogar von Strahlenschutzrichtlinien in Deutschland gefordert ist, wird häufig auf ihren Einsatz wegen der schlechten Handhabbarkeit verzichtet. Nun sind neue Ausführungen verfügbar, die leichter zu handhaben sind und eine leichtere Anwendbarkeit und dadurch Akzeptanz versprechen. In dieser Arbeit werden zwei neue Patientenabschirmungen auf ihre Abschirmeigenschaften und ihre Einsetzbarkeit hin untersucht und mit einem Schilddrüsenschutz, der typischerweise als Teil der persönlichen Schutzausrüstung des Personals verwendet wird, verglichen.

Material und Methoden: Die Reduktion der Organdosen von Schilddrüse, Sternum und Mamma wurden mit Thermolumineszenzdetektoren in einem anthropomorphen weiblichen Phantom gemessen. Außerdem wurde der Einfluss der Einstellparameter (Lage der Übersichtsaufnahme) untersucht.

Ergebnisse: Je nach verwendeter Patientenabschirmung konnte die Organdosis der Schilddrüse um 5-24\%, die Organdosis des Sternums um $25-48 \%$ und die Mammadosis um 25 - 70\% reduziert werden. Eine kraniale Verschiebung der Übersichtsaufnahme um $25 \mathrm{~mm}$ reduzierte diese Organdosen um $12-15 \%$.

Schlussfolgerungen: Durch die Verwendung von Patientenabschirmungen können Organdosen deutlich gesenkt werden. Die neuen Modelle sind einfach anzuwenden und zeigten keine Rekonstruktionsartefakte. Es sollte daher ein Schutz verwendet werden, der auf den Patienten nur aufgelegt wird und nicht um den Hals gelegt werden muss. Außerdem sollte die Übersichtsaufnahme so klein wie möglich um die Untersuchungsregion gehalten werden.

\section{Abstract \\ $\nabla$}

Purpose: Although the use of thyroid shields for patients for head CT examinations is reasonable and even required by German regulations, so far available shields are often not used due to difficult applicability. New shields that are easier to use and therefore may gain wider acceptance and more frequent use are now available. In this work two new patient shields are investigated regarding their dose reduction effectiveness and applicability and compared to a thyroid/sternum shield typically used as a part of personal protective equipment.

Materials and Methods: The reduction of organ doses for thyroid, sternum and mamma were measured with thermoluminescence detectors in an anthropomorphic female phantom. Additionally, the influence of the length or position of the overview scan at the beginning of the CT examination was taken into account.

Results: Depending on the patient shield, a reduction of the organ doses for thyroid of $5-24 \%$, for sternum of $25-48 \%$ and for mamma of $25-70 \%$ could be found. A shift of $25 \mathrm{~mm}$ in the cranial direction for the overview scan resulted in a reduction of these organ doses of $12-15 \%$.

Conclusion: Patient shields for cranial CT examinations provide a considerable dose reduction. New models are easily applied and no decrease in image quality through reconstruction artifacts could be found. Therefore, it is advised to use shields which are applied upon the patient without the need to be wrapped around the neck and the overview scan should be positioned as close as possible to the examined region.

Key Points:

- New shields provide a compromise between usability and radiation protection.

- Patient shields reduce organ doses even when not directly exposed. 
Kernaussagen:

- Neue Patientenabschirmungen bieten einen guten Kompromiss zwischen Handhabbarkeit und Strahlenschutz.

- Die untersuchten Schutzmittel reduzieren die Organdosen auch von nicht direkt exponierten Organen.

- Der Übersichtsscan trägt beträchtlich zu Organdosen außerhalb der Scanregion bei.

- Die Abschirmfaktoren werden stark durch die Lage der Untersuchungsregion beeinflusst.

\section{Introduction}

Computed tomography with its growing number of examinations is the largest contributor to the collective dose caused by medical examinations [1]. The reduction of its dose contribution without losing any relevant diagnostic information is of importance according to the ALARA principle.

The German guideline for surveyors for X-ray devices [2] demands the availability of thyroid shields for patients for head CT examinations. Common thyroid/sternum shields from personnel radiation protection vests have to be wrapped around the patient's neck which is not always acceptable to patients who report feeling choked. Additionally if the patient is not cooperative, it is rather difficult to place the shield around the neck with the patient already lying on the couch.

Another important aspect is that the gantry tilt to avoid direct exposure of the eye lenses may lead to reconstruction artifacts in the last reconstructed slices in the caudal direction. This may occur if a large gantry tilt and spiral acquisition with large collimation of a multi-slice CT is used for the examination and therefore the scanning range reaches the neck part of the shield.

All these factors make it tempting to not use any shielding and therefore the acceptance of radiation protection shielding by radiological technologists as well as patients is low although studies for other medical imaging techniques like cone beam CT e.g. used in dentistry $[3,4]$ or for CT examinations of other regions than the head $[5,6]$ have shown the general dose reduction potential. There are also studies which present comparison measurements of thyroid doses for head-neck scans with the thyroid gland partly in the direct beam [6] or entrance doses for the thyroid gland with prototype shields focusing on the direct beam [7] with promising results.

However, new shields that address these applicability issues are available and their effectiveness for dose reduction is reported in this article.

\section{Materials and Methods \\ $\nabla$}

Measurements were done using LiF: $\mathrm{Mg}, \mathrm{Cu}, \mathrm{P}$ thermoluminescence detector (TLD) rods GR-200A in a CIRS ATOM anthropomorphic female adult phantom at a SIEMENS Somatom Sensation 64 multi-slice CT scanner. A calibration process connecting air kerma measurements from a manufacturer calibrated CTDI100 pencil type ionization chamber PTW T30009, ASHLAND Gafchromic XR-QA2 radiochromic film and the TLD GR-200A in the direct beam of the same scanner was used.
- The overview scan contributes considerably to out of field organ doses.

- Shielding factors are greatly influenced by the positioning of the examination field.

Citation Format:

- Liebmann M, Lüllau T, Kluge A et al. Patient Radiation Protection Covers for Head CT Scans - A Clinical Evaluation of Their Effectiveness. Fortschr Röntgenstr 2014; 186: 1022-1027

\section{CT scanner and protocol}

All irradiations were done using a SIEMENS Somatom Sensation 64 scanner. This is a 64-slice spiral CT with automated tube current modulation which was turned off for calibration.

Since a clinical CT examination consists of two parts, i.e., the overview scan to locate the scanning region and the slice image acquisition, both were taken into account. In $\bullet$ Fig. 1, $\bullet$ Table 1 the initial overview scan which was done at $120 \mathrm{kV}, 97 \mathrm{mAs}$, $0.6 \mathrm{~mm}$ collimation, $256 \mathrm{~mm}$ length and a tube angulation of $90^{\circ}$ is shown. Table 1 also lists the examination protocol used for the slice image acquisition which is the standard protocol for cranial CT examinations for adults. It is a sequential acquisition scanning protocol and thus induces no overranging but since the used scanner is a multi-slice scanner it is subject to overbeaming.

\section{Phantom}

To determine the effectiveness of the investigated thyroid shields, organ doses were measured in a CIRS ATOM anthropomorphic female adult phantom "Irene". $190 \mathrm{~cm}^{3}$ breast attachments were used as well as arm attachments. This phantom has $5 \mathrm{~mm}$ holes arranged in a $1.5 \mathrm{~cm} \times 1.5 \mathrm{~cm}$ grid. Those holes were filled with plugs of the corresponding tissue and for TLD placement specially drilled plugs were used. TLDs were placed at locations representing the thyroid gland (10 TLDs), sternum ( 9 TLDs) and both breasts ( 4 TLDs each) of the phantom. According to the concept of organ doses, readouts of TLDs representing the same organ

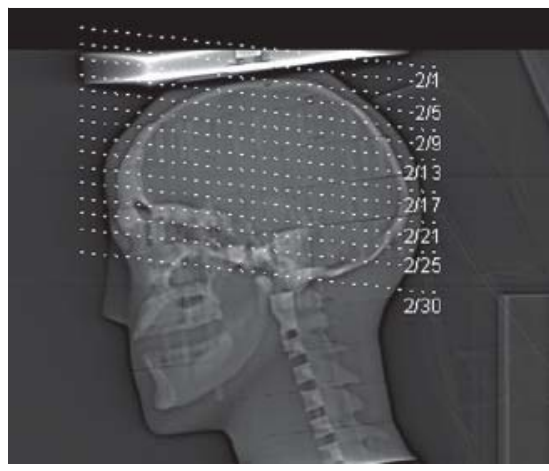

Fig. 1 Overview scan at the beginning of the examination with the positioning of the scanning region.

Abb. 1 Übersichtsaufnahme zu Beginn der CT-Untersuchung zur Lokalisierung der Scan-Region.

Table 1 Standard CT examination protocol for head CT scans used in this study.

Tab. 1 Genutztes CT-Untersuchungsprotokoll für standard Schädel-CTScans.

\begin{tabular}{|lcclllll|} 
description & $\mathbf{k V p}$ & $\mathbf{m A s}$ & $\begin{array}{l}\text { DLP/ } \mathbf{m G y} \\
\mathbf{c m}\end{array}$ & $\begin{array}{l}\mathbf{C T D I}_{\mathbf{v o l}} \\
\mathbf{m G y}\end{array}$ & $\mathbf{p}$ & collimation/mm \\
\hline overview & 120 & 97 & - & - & - & $1 \times 0.6 \mathrm{~mm}$ \\
\hline series 1 & 120 & 400 & 793 & 55.62 & 1.0 & $24 \times 1.2 \mathrm{~mm}$ \\
\hline
\end{tabular}




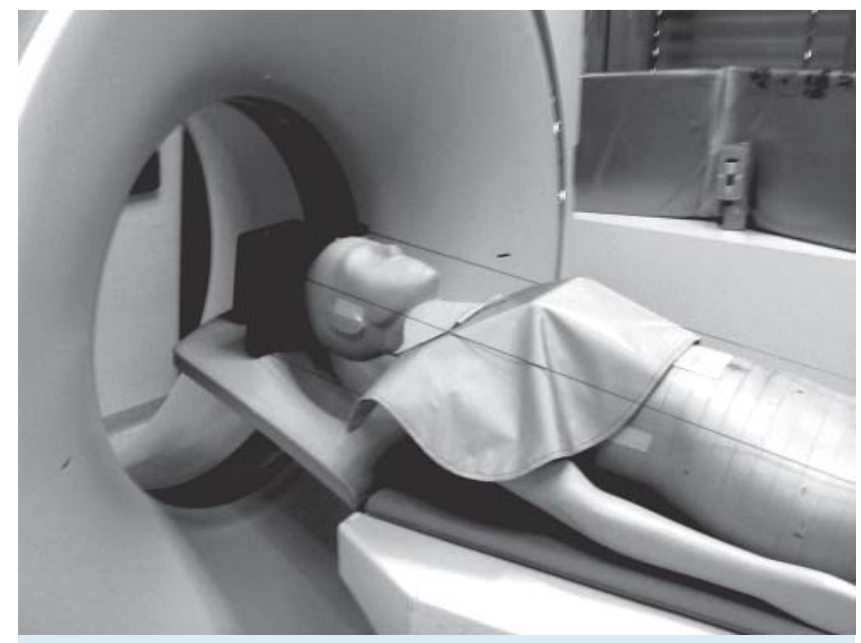

Fig. 2 MAVIG RP648 cover for thyroid, sternum, chest and shoulder area with $0.35 \mathrm{~mm}$ lead equivalent inlay placed on the CIRS ATOM anthropomorphic female adult phantom Irene.

Abb. 2 MAVIG RP648 Protektor für die Schilddrüse, Sternum, Brust und Schultergelenke mit 0,35 mm bleiäquivalentem Inlet am CIRS ATOM anthropomorphen Phantom Irene.

were averaged to one organ dose. The location for the thyroid gland was determined in close collaboration with the clinic for nuclear medicine at the Pius Hospital Oldenburg. The phantom filled with TLDs was scanned at the same CT unit where the calibration was done. It was placed on the couch and positioned according to the laser markings.

\section{Patient shields}

The patient shields investigated in this study are the newly developed MAVIG RP648 cover for thyroid, sternum, chest and shoulder area ( $\bullet$ Fig. 2) with $0.35 \mathrm{~mm}$ lead equivalent protective inlay, F\&L MEDICAL PRODUCTS thyroid shield ( $\bullet$ Fig. 3 ) with $0.06 \mathrm{~mm}$ lead equivalent and a MAVIG RA615 thyroid/sternum shield for combination with personnel protection coats ( $\bullet$ Fig. 4) with $0.5 \mathrm{~mm}$ lead equivalent. These shields were placed on the phantom before the overview scan and therefore the measured organ doses represent a whole CT examination consisting of the overview scan as well as the actual image acquisition for one scanning series.

\section{Thermoluminescence dosimeters}

TLD100H equivalent dosimeters of type GR-200A and a size of $1 \mathrm{~mm} \times 1 \mathrm{~mm} \times 6 \mathrm{~mm}$ were used to measure organ doses in the phantom. These rods are made of a ceramic composed of LiF doped with $\mathrm{Mg}$, $\mathrm{Cu}$ and $\mathrm{P}$.

Tempering was done using a PTW TLDO 1321 temper oven at $240{ }^{\circ} \mathrm{C}$ for $2 \mathrm{~h}$. Subsequently the TLDs were cooled down inside the oven while the door was kept closed to ensure a steady but slow and reproducible cooling process.

For TLD readout a Harshaw 3500 TLD reader with a fitting planchet for TLD rods was used. All measurements were done at least $2 \mathrm{~h}$ after irradiation to avoid initial short-term fading. The timetemperature profile for readout consisted of a preannealing phase at $130{ }^{\circ} \mathrm{C}$ for $10 \mathrm{~s}$, a heating phase at $8 \mathrm{~K} / \mathrm{s}$ up to $240^{\circ} \mathrm{C}$ and a subsequent acquiring phase for $23.3 \mathrm{~s}$ together with regards to previous studies [8-10]. To remove remaining signals, an annealing phase at $240^{\circ} \mathrm{C}$ for $10 \mathrm{~s}$ was done after the readout.

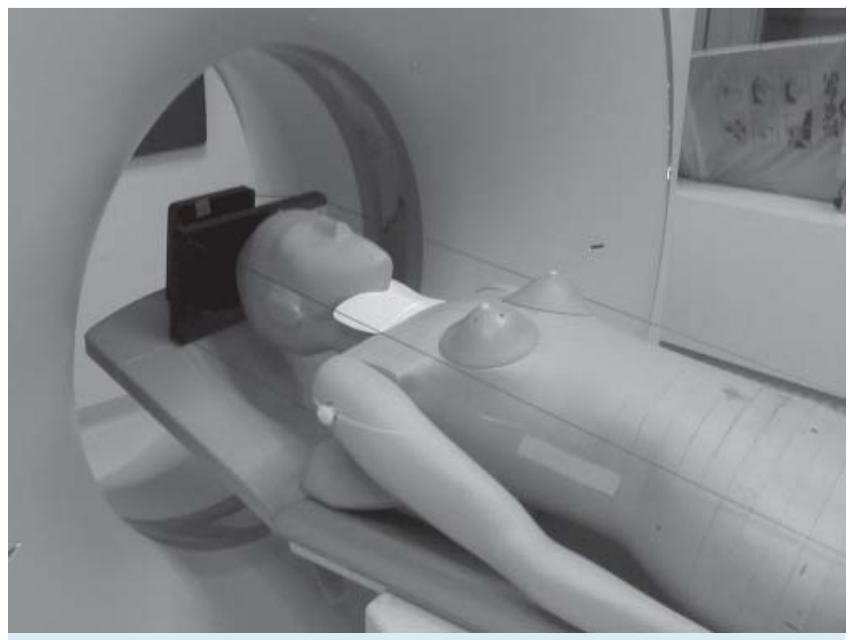

Fig. 3 F\&L Medical Products Thyroid Shield with $0.06 \mathrm{~mm} \mathrm{~Pb}$ equivalent placed at the CIRS ATOM phantom.

Abb. 3 F\&L Medical Products Thyroid Shield mit 0,06 mm Pb Äquivalent am CIRS-ATOM-Phantom.

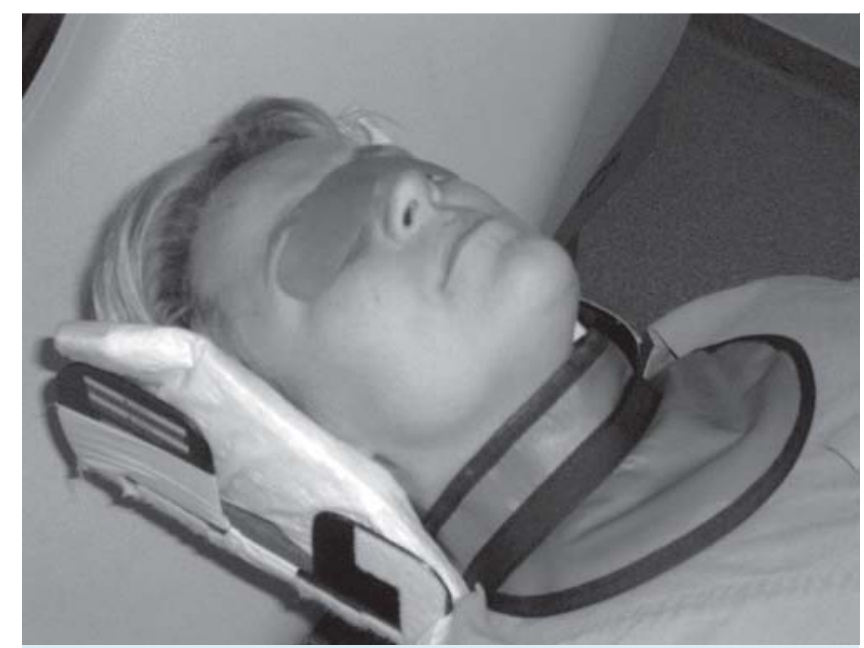

Fig. 4 MAVIG RA615 thyroid/sternum shield.

Abb. 4 MAVIG RA615 Schilddrüsen-Sternumschutz.

The stability of the readout system was tested every 20 measurements via a photomultiplier tube (PMT) test light and noise measurement. The PMT test light measurement showed a $2 \sigma$ deviation of $4.8 \%$ while the noise varied by $22 \%$ at a $2 \sigma$ confidence interval.

\section{Calibration process}

Irradiation for calibration free-in-air was done at $120 \mathrm{kV}$, $250 \mathrm{mAs}$ and a total collimation of $28.8 \mathrm{~mm}$ using a single rotation of the X-ray tube without couch movement. This peak voltage was chosen because it is used in the standard protocol for cranial CT examinations and a calibration factor for the pencil type ionization chamber is available.

The first part of the calibration was the acquisition of the free-inair beam profile along the table axis with radiochromic film Gafchromic XR-QA2 from ASHLAND. Since these films show a nonlinear dose response, a first dose-response calibration was done 
with a PTW 31010 ionization chamber. The film was cut into strips with a width of $2 \mathrm{~cm}$ and placed in the isocenter of the CT scanner using a thin mounting to tighten the film strip. Irradiation was done with $28.8 \mathrm{~mm}$ total collimation and $120 \mathrm{kV}$ and a stationary scan protocol. An EPSON Expression 10000XL CCD scanner was used to scan the radiochromic film in reflection mode, 72 dpi resolution and 48 bit color depth, but only the red color channel was used for analysis according to previous publications $[11,12]$.

This profile $P V(x)$ (pixel value) was then integrated in a length of $100 \mathrm{~mm}$ centered on the primary beam and normalized against the absorbed dose length product $D L P_{\text {Air }}$ measured with the CTDI chamber PTW T30009 which was corrected for the influence of air pressure, temperature and beam quality. Thus the calibration factor $k$ :

$\mathrm{k}=\frac{\mathrm{DLP}_{\text {Air }}}{\int_{-50 \mathrm{~mm}}^{50 \mathrm{~mm}} \operatorname{PV}(\mathrm{x}) \mathrm{dx}}$

was calculated and used to acquire the calibrated profile shown in - Fig. 5.

In the final part of the calibration, 5 TLDs at a time were placed in the center of the CT beam and irradiated with the same settings. Only 5 TLDs at a time were irradiated to avoid dose variation caused by the heel effect. The dose at the TLD positions was then determined using the previously acquired and cross-calibrated dose profile with an average absorbed dose value for a range of $5 \mathrm{~mm}$ centered on the central beam axis.

\section{Uncertainties}

The relative values for dose reduction are only subject to the uncertainty in reproducibility. This was tested by 12 recalibrations for all used TLDs and a determination of the $2 \sigma$ deviation which was within $4.5 \%$.

The uncertainties of the absolute dose values consisting of the uncertainty of the beam quality correction, calibration factor

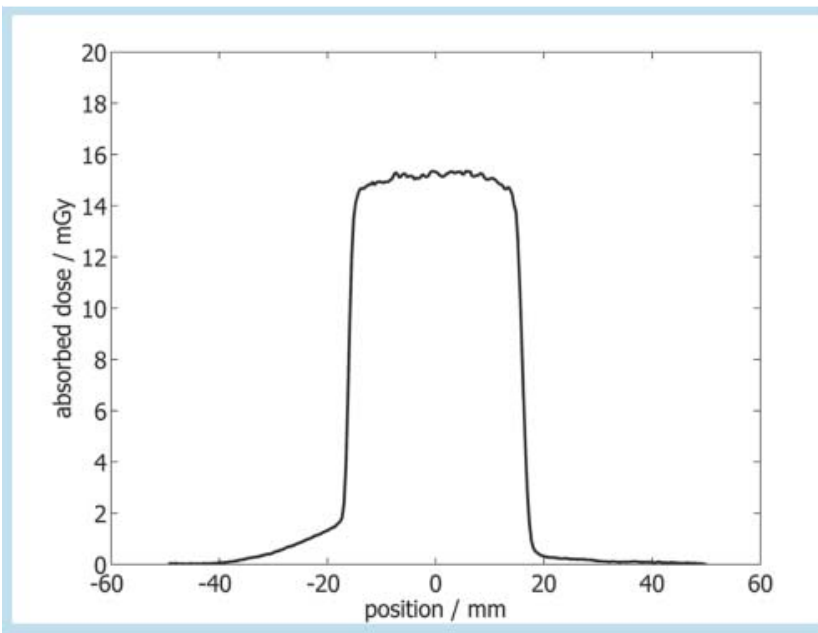

Fig. 5 Calibrated absorbed dose profile at field of view center for the SIEMENS Somatom Sensation 64, acquired with $120 \mathrm{kV}, 100 \mathrm{mAs}, 28.8 \mathrm{~mm}$ total collimation, $1 \mathrm{~s}$ rotation time. Measured with ASHLAND Gafchromic XR-QA2 and an EPSON Expression $10000 X \mathrm{X}$.

Abb. 5 Kalibriertes Dosisprofil im Zentrum des Field of View eines SIEMENS Somatom Sensation 64, aufgenommen mit $120 \mathrm{kV}, 100 \mathrm{mAs}$, $28.8 \mathrm{~mm}$ Gesamtkollimation und $1 \mathrm{~s}$ Röhrenrotation. Gemessen mit ASHLAND Gafchromic XR-QA2 und einem EPSON Expression 10000XL. and dose measurement with the film and TLDs total 6.9\%. This value is composed of the following components:

Absolute determination of the absorbed dose is influenced by additional factors. First is the $D L P_{\text {Air }}$ measurement with an air pressure, temperature and beam quality correction. Uncertainties for the pressure and temperature are small compared to the uncertainty of the manufacturer calibration factor and therefore were neglected in the subsequent analysis process. The combined uncertainty for beam quality correction and calibration factor accounts for $5 \%$ [13].

While calibration was done in the direct CT beam, the absorbed dose was measured in a mixed radiation field of scattered photons and the TLDs of the first thyroid phantom slice were exposed to the direct beam from the overview scan. Previous studies [14-16] found only a slight variation in energy correction factors for this energy range and therefore no further corrections were applied.

The second additional factor for the uncertainty of the calibration is the dose profile measurement due to different sensitivity of the film and the reproducibility of the scanning process. This measurement was done three times and a $2 \sigma$ deviation of $1.7 \%$ was found.

\section{Preliminary study - influence of the overview scan}

Since the investigated organs are not located in the direct beam of the actual CT image acquisition but in the scattering region, the dose from the slice acquisition is expected to be low. Therefore, the positioning of the overview scan becomes an important factor. Depending on the caudal length and positioning of the overview scan, the thyroid gland may be in the direct beam of the overview scan and therefore this preliminary scan contributes considerably to the thyroid dose.

To evaluate the effect of different positioning, two measurements of organ doses without any shielding but using overview scans shifted $25 \mathrm{~mm}$ cranially were done. For both scans the actual CT reconstruction slices were positioned equally. This shifting represents the variation in positioning of the overview scan due to the slightly variable turn-on timing of the X-ray tube in the used CT scanner.

\section{Results}

$\nabla$

The absolute absorbed dose values for the thyroid, sternum and mamma without any shielding for the whole examination were $2.65 \mathrm{mSv}, 0.65 \mathrm{mSv}$ and $0.27 \mathrm{mSv}$, respectively. The overview scan alone contributed $0.49 \mathrm{mSv}, 0.11 \mathrm{mSv}$ and $0.04 \mathrm{mSv}$, respectively.

The results for the shifted overview scan as well as the different patient shields are shown in $\bullet$ Table 2 and $\bullet$ Fig. 6. The organ doses for the thyroid, sternum and breasts are reduced by $12 \%, 15 \%$ and $14 \%$, respectively, through the shifting of the overview scanning area $25 \mathrm{~mm}$ cranially.

The new MAVIG RP648 protector with $0.35 \mathrm{~mm}$ lead equivalent decreased the organ doses for the thyroid, sternum and breasts by $11 \%, 43 \%$ and $70 \%$, respectively.

A decrease of $5 \%, 25 \%$ and $27 \%$, respectively, could be found for the thin $0.06 \mathrm{~mm}$ lead equivalent single use product from $\mathrm{F}$ \& L Medical Products.

The MAVIG RA615 thyroid/sternum shield for personnel protection with the highest lead equivalent of $0.5 \mathrm{~mm}$ decreased the organ doses by $33 \%, 55 \%$ and $39 \%$, respectively.

None of the shields caused reconstruction artifacts although the distance from the last image slice to the dorsal part of the MAVIG RA615 was only $33 \mathrm{~mm}$. 
Table 2 Measured organ doses for 3 different patient shields, the complete CT examination with overview scan shifted $2.5 \mathrm{~cm}$ cranially and the overview scan alone.

Tab.2 Gemessene Organdosen für drei verschiedene Patientenabschirmungen, einer kompletten CT-Untersuchung mit um $2,5 \mathrm{~cm}$ kranial verschobener Übersichtsaufnahme und nur der Übersichtsaufnahme allein.

\begin{tabular}{|llll|} 
shield & $\begin{array}{l}\text { thyroid gland } \\
\text { D/mSv }\end{array}$ & $\begin{array}{l}\text { sternum } \\
\text { D/mSv }\end{array}$ & $\begin{array}{l}\text { mamma } \\
\text { D/mSv }\end{array}$ \\
\hline no shield & 2.65 & 0.65 & 0.27 \\
\hline overview scan shifted $2.5 \mathrm{~cm}$ & 2.32 & 0.56 & 0.23 \\
\hline MAVIG RP648 & 2.36 & 0.37 & 0.08 \\
\hline F \& L Thyroid Shield & 2.50 & 0.49 & 0.20 \\
\hline MAVIG RA615 & 1.77 & 0.29 & 0.16 \\
\hline overview scan only & 0.49 & 0.11 & 0.04 \\
\hline
\end{tabular}

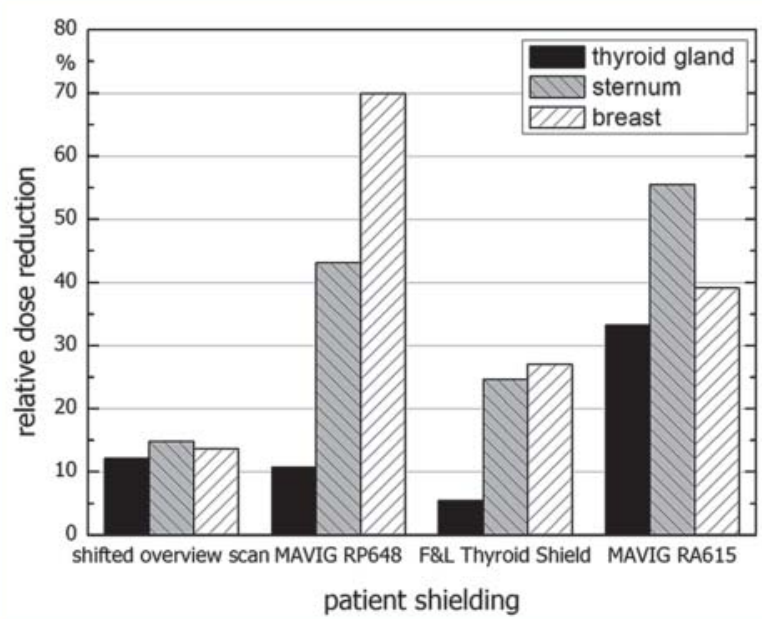

Fig. 6 Organ dose reduction of different patient shields and effect of cranial shifting of the overview scan.

Abb. 6 Organdosisreduktion durch verschiedene Patientenabschirmungen und der Effekt einer kranialen Verschiebung der Übersichtsaufnahme.

\section{Discussion}

$\nabla$

All investigated patient shields reduced organ doses. In a patient study Ngaile et al. [7] demonstrated the fundamental possibility to reduce the entrance surface dose to the thyroid using thyroid shields of sponge material and sheets of $\mathrm{Pb}$ with an equivalent thickness of 0.125 and $0.25 \mathrm{~mm}$. They found a reduction of the entrance dose of $37 \%$ and $51 \%$, respectively, which is comparable to the results in this study. Compared to the previous study by Buchgeister et al. [6] who found a thyroid dose reduction by $43 \%$ from $7.9 \mathrm{mSv}$ to $4.5 \mathrm{mSv}$ (Bismuth shield with $0.125 \mathrm{~mm} \mathrm{~Pb}$ equivalent thickness) for a head-neck CT examination including part of the thyroid with a scan length of $210 \mathrm{~mm}$, a much lower absolute thyroid dose was measured in this study due to the shorter scan length of only $143 \mathrm{~mm}$.

As to be expected, the largest reduction in thyroid dose was achieved by the shield with the largest lead equivalent. This is an expected result since the first phantom slice with TLDs, which represented the thyroid gland, was in the direct beam of the overview scan.
The absorbed dose to the sternum and breasts is always the result of scattering processes. One source is extra-focal radiation which is best shielded with large coverings. This is shown by the large reduction in breast dose by the MAVIG RP648 shield.

Another source of absorbed dose due to scattering is scattering inside the phantom itself. Due to the phantom placement and gantry angulation during cranial CT examinations, scattered photons originating in the scanning region exit the phantom at the chin/neck region and re-enter the phantom's body at the sternum or breast area. This effect is suggested by the breast dose reduction by the F\&L Thyroid Shield and MAVIG RA615 which do not cover the breasts.

Since the phantom has a fixed neck and a patient would bend his neck, the geometry changes slightly. A patient's sternum as well as mamma would be closer to the scanning region and therefore patient organ doses are expected to be higher than the measured ones in which case the benefit of reduction of organ doses would be even greater.

The F\&L Thyroid Shield provides the least organ dose reduction due to its small $0.06 \mathrm{~mm}$ lead equivalent absorption factor but still has a benefit if a disposable is required for sanitary reasons or the planned CT scanning range encloses the thyroid gland and therefore reconstruction artifacts are to be expected if a shield with a larger lead equivalent is used.

From a practical point of view, shields that simply need to be put on the patient without any wrapping are of advantage and although the MAVIG RP648 has only $0.35 \mathrm{~mm}$ lead equivalent it comparatively reduces the sternum dose with respect to the $0.5 \mathrm{~mm}$ lead equivalent MAVIG RA615. This practical advantage is to some degree a disadvantage for radiation protection because there is no shielding in the dorsal direction and depending on the stiffness of the shield the covering of lateral neck parts can be improved.

Regarding the different sensitivity of the investigated organs, special attention has to be paid to the female breast. According to the lifetime attributable risk of cancer incidence for the female breast $-15.9 \%$, red bone marrow $-7.0 \%$ and thyroid $-1.6 \%$ of all cancers for a 40 -year-old female [17], the large dose reduction of the MAVIG RP648 becomes more relevant for radiobiological considerations.

To sum up those results: for male patients the MAVIG RA615 should be used if possible. If there are difficulties which prevent its use (e. g. choking, non-cooperative), the MAVIG RP648 should be used. For female patients the MAVIG RP648 should be used in the first place. If a disposable is required, the F\&L Thyroid Shield can be used to provide radiation protection.

All those patient shields can be combined with proper examination planning, which means an as short as possible overview scan at the beginning of the examination since a $25 \mathrm{~mm}$ shift leads to a thyroid dose reduction similar to that of a $0.35 \mathrm{~mm}$ lead shield. For suboptimal setup conditions or much longer CT scanning ranges which may occur during clinical practice, the absolute dose reduction of all these shields increases since the absolute organ doses increase too. Therefore, the longer the overview scan and CT scanning range, the more effective these shields are.

Attention must be paid if the scanning region for the slice acquisition reaches or gets close to the shield and thus a head-neck study is performed. If a tube current modulated scanning protocol is used with an algorithm based on overview-scan data, this algorithm would compensate the shielding by increasing the tube current and thus increasing the absorbed dose. In this case 
the shield should only be placed on the patient after the initial overview scan(s), which is only possible with the new models. If an algorithm based on online detector data is used, no shielding can be used.

\section{Clinical Relevance}

- Thyroid shields for patients have to be used during head CT examinations by German law.

- Decision assistance is offered to choose the best type of shield taking the handling and the state of the patient into consideration.

- Reduction of patient exposure is achieved with minimal effort in accordance with the ALARA principle.

\section{References}

1 Bundesamt für Strahlenschutz. Radiation Exposures from Medical Applications. Annual Report 2012: 3-4

2 Richtlinie für Sachverständigenprüfungen nach der Röntgenverordnung (SV-RL). Bundesministerium für Umwelt, Naturschutz und Reaktorsicherheit; 2009

3 Goren AD, Prins RD, Dauer LT et al. Effect of leaded glasses and thyroid shielding on cone beam CT radiation dose in an adult female phantom. Dento Maxilla Facial Radiology 2013; 42: 20120260

4 Qu X, Li G, Zhang Z et al. Thyroid shields for radiation dose reduction during cone beam computed tomography scanning for different oral and maxillofacial regions. European Journal of Radiology 2012; 81: e376-e380

5 Hoang JK, Yoshizumi TT, Choudhury KR et al. Organ-based dose current modulation and thyroid shields: techniques of radiation dose reduction for neck CT. American Journal of Roentgenology 2012; 198: $1132-1138$
6 Buchgeister M, Sieburg St, Roll M et al. Dosisreduktion der Augen- und Schilddrüsenexposition durch Abschirmung in der klinischen Thorax Computertomographie. Fortschr Röntgenstr 2012: 184-WI_PO4

7 Ngaile JE, Uiso CB, Msaki P et al. Use of lead shields for radiation protection of superficial organs in patients undergoing head CT examinations. Radiation Protection Dosimetry 2008; 130: 490-498

8 Horowitz YS, Horowith A. Characterisation of LiF:Cu, Mg, P (GR-200) for personnel thermoluminescence dosimetry. Radiation Protection Dosimetry 1990; 33: 279-282

9 Pautsch M. Untersuchung zur Optimierung der physikalisch-technischen Parameter beim Auswerten und Tempern von Thermolumineszenzdosimetern des Typs TLD-100H. Hannover: Dissertation Tierärztliche Hochschule Hannover; 2012

10 Tang $K$, Zhao J, Shen $W$ et al. Influence of Readout Parameters on TL Response, Re-usability and Residual Signal in LiF:Mg, Cu, P. Radiation Protection Dosimetry 2002; 100: 353-356

11 Martin CJ, Gentle DJ, Sookpeng S et al. Application of Gafchromic film in the study of dosimetry methods in CT phantoms. Journal of Radiological Protection 2011; 31: 389-409

12 Rampado O, Garelli E, Deagostini S et al. Dose and energy dependence of response of Gafchromic XR-QA film for kilovoltage X-ray beams. Physics in Medicine and Biology 2006; 51: 2871 -2881

13 PTW-Freiburg. Calibration sheet. Freiburg: 2010

14 Donadille L, Carinou E, Ginjaume M et al. An overview of the use of extremity dosemeters in some European countries for medical applications. Radiation Protection Dosimetry 2008; 131: 62 - 66

15 Davis SD, Ross CK, Mobit PN et al. The response of LiF thermoluminescence dosemeters to photon beams in the energy range from $30 \mathrm{kV}$ $\mathrm{X}$-rays to Co-60 gamma rays. Radiation Protection Dosimetry 2003; 106: $33-43$

16 Olko P. Microdosimetric Interpretation of Thermoluminescence Efficiency of LiF:Mg, Cu, P (MCP-N) Detectors for Weakly and Densely Ionising Radiations. Radiation Protection Dosimetry 1996; 65: 151 - 158

17 Committee to Assess Health Risks from Exposure to Low Level of Ionizing Radiation. Health risks from exposure to low levels of ionizing radiation: BEIR VII phase 2. Washington, DC: National Academies; 2006: 550 